\title{
The Management of Kienböck Disease: A Survey of the ASSH Membership
}

\author{
Jonathan R. Danoff, MD $\quad$ Derly O. Cuellar, MD ${ }^{1} \quad$ Jane O, MD ${ }^{1} \quad$ Robert J. Strauch, MD ${ }^{1}$ \\ ${ }^{1}$ Department of Orthopaedic Surgery, Columbia University Medical \\ Center, New York \\ J Wrist Surg 2015;4:43-48.

\begin{abstract}
Address for correspondence Robert J. Strauch, MD, Department of Orthopaedic Surgery, Columbia University Medical Center, 622 West 168th Street, PH-1119, New York, NY 10032 (e-mail: robertjstrauch@hotmail.com).
\end{abstract}

\begin{abstract}
Background The purpose of this study was to determine the current trends and common practices for the treatment of Kienböck disease at different stages.

Question/Purpose To determine the current trends and common practices by hand surgeons for the treatment of Kienböck disease.

Methods A survey with hypothetical Kienböck disease cases stratified by the Lichtman staging system was distributed to the American Society for Surgery of the Hand (ASSH) members. Questions and responses reflected common treatment strategies.

Results Of a total of 375 worldwide respondents, preferred treatments of Kienböck disease were as follows: for Stage I disease, an initial trial of splinting was favored (74\%), followed by radial shortening osteotomy for continued symptoms. For Stage II disease, $63 \%$ of surgeons preferred surgical intervention, particularly radial shortening osteotomy. For Stage Illa with negative ulnar variance, $69 \%$ chose radial shortening osteotomy. Responses were heterogeneous for Stage Illa Kienböck with positive variance, and capitate shortening osteotomy and vascularized bone grafting were preferred. Salvage procedures predominated for Stage IIIb disease, including proximal row carpectomy

Keywords

- Kienböck disease

- wrist

- carpal

- arthritis

- lunate

- survey

- treatment

- trends (PRC; 42\%), intracarpal arthrodesis (21\%), and total wrist fusion (10.7\%). Similarly, Stage IV disease was treated by $87 \%$ of respondents by either PRC or wrist fusion. Without regard to stage of disease, $90 \%$ of participants reported using the same Lichtman staging to guide treatment and would also alter treatment strategy based upon ulnar variance.

Conclusions Most respondents used Lichtman staging and ulnar variance to guide treatment decisions. Results indicate that the most common surgical treatments were radial shortening osteotomy for early disease and PRC in later stages.

Level of Evidence Level IV, Economic/Decision Analysis
\end{abstract}

In 1910 Robert Kienböck, an Austrian radiologist, described a cohort of patients with osteomalacia of the lunate. ${ }^{1}$ Although he was not the first physician to describe this phenomenon, he believed that these changes were due to an avascular necrosis of the lunate as a result of a traumatic insult. $^{2}$ The etiology of Kienböck disease remains a topic of debate and controversy. ${ }^{3,4}$ A classification of Kienböck disease was published by Stahl in $1947,{ }^{5}$ and in an effort to describe the disease better Lichtman et al introduced a modified classification system, which remains the most commonly used today, with four broad stages of disease. ${ }^{6}$ This classification was originally based on radiographs, although in later papers the use of advanced imaging modalities such as magnetic resonance imaging (MRI) was included. ${ }^{6-10}$ This classification system has good interobserver reliability. ${ }^{7,8,10-15}$
Copyright (c) 2015 by Thieme Medical Publishers, Inc., 333 Seventh Avenue, New York, NY 10001, USA. Tel: +1(212) 584-4662. 
There are several treatment options available for managing Kienböck disease, and they are primarily based on the stage of the disease on presentation. The goals for treatment include pain relief, motion preservation, and maintenance of strength and function, ${ }^{16}$ although there is insufficient evidence supporting the superiority of any single treatment procedure that can consistently and reliably achieve these goals. ${ }^{17}$ Additionally, there is a lack of level 1 evidence from large, prospective, randomized trials comparing different treatment options for Kienböck disease, as this is a rare disease making it difficult to obtain enough power to obtain statistically significant results ${ }^{18-31}$; thus, the aim of this study was to determine the current trends and common practices by hand surgeons for the treatment of Kienböck disease at different Lichtman stages.

\section{Materials and Methods}

After institutional review board approval, a questionnaire was developed and members of the American Society for Surgery of the Hand (ASSH) were surveyed. The survey was conducted electronically with an Internet-based questionnaire distributed via email to ASSH national and international members using SurveyGizmo (Surveygizmo.com, Boulder, CO, USA). Surgeons were presented with several cases of Kienböck disease at different Lichtman classification stages and asked to choose their optimal intervention from a list of operative and nonoperative modalities. In addition, they were asked to answer several general and demographic questions.

The questionnaire comprised four clinical scenarios of Kienböck disease based on the Lichtman classification. Each case described the same "typical" patient, a right-handdominant healthy adult male laborer with a 6-month history of atraumatic wrist pain limiting his ability to work. These case presentations varied primarily on radiographic findings. Although radiographic images were not provided, descriptions of the standard posteroanterior (PA), oblique, and lateral radiographs of the affected wrist were given and a radiographic diagnosis was provided as a closing statement, e.g., "A diagnosis of Stage I Kienböck's disease is made." This was done to ensure that all respondents understood the stage of disease they were treating and to avoid differences in radiographic interpretation of the diagnosis. After each case presentation, a question about preferred treatment was asked. Answer choices provided a wide range of treatment options including nonoperative management with immobilization, operative, and salvage procedures. Most of the answer choices consisted of tiered response, which further specified their previous answer. For example, if the surgeon chose "trial of splinting/cast immobilization," then a second set of answer choices would present themselves to answer the question of "for how long?" Similarly, if the treatment chosen was "radial shortening" or "core decompression," the subsequent answer choices were about how much shortening-"0 mm (width of saw only), $2 \mathrm{~mm}, 3 \mathrm{~mm}$, or $4 \mathrm{~mm}$ "-or "radius core decompression, ulna core decompression, or both radius and ulna core decompression." Furthermore, respondents had the opportunity to provide free text answers if desired. Treatment options included trial of splinting/immobilization, core decompression, vascularized bone graft, external fixation with additional procedures, pinning of scaphotrapeziotrapezoidal (STT) or scapholunate joint without external fixation, radial shortening osteotomy, radial wedge osteotomy, capitate shortening osteotomy, intercarpal arthrodesis, lunate excision, proximal row carpectomy (PRC), or total wrist fusion. The cases presented were Stage I, IIla with negative variance, IIIa with positive variance, and IIIb. Stage II and IV treatments were asked as addenda to cases one (Stage I) and four (Stage IIIb). For example, after the preferred treatment choice was given for the first case presentation, the subsequent question would read "would your preferred treatment change if the $\mathrm{x}$-rays revealed lunate sclerosis without collapse (i.e., Stage II Kienböck's disease)?"; thus, minimizing the questionnaire burden on surgeons by having the same case being presented consecutively. Additionally, questions were asked regarding whether the respondent valued the Lichtman classification scheme and whether the respondent used ulnar variance to guide treatment, and demographic data were collected with questions focused on type of residency and fellowship training and experience.

Questionnaire responses were collected anonymously and electronically tabulated. Results were expressed as means for continuous variables and as percentage for frequency distribution of categorical data. Since the survey software allowed respondents to skip questions without submitting a response, the number of responses per question varied throughout the questionnaire. Respondents were excluded if they completed less than $75 \%$ of the questionnaire. To diminish selection bias, if a response to a specific question was missing, the respondent was excluded from the analyses of that specific question only.

\section{Results}

The results from 390 participants were received and 15 respondents were excluded for incomplete data, leaving 375 survey responses for inclusion in the analysis. Respondents had an average length of practice of 20 years (range, 1-50 years) and comprised 16 countries including $91 \%$ from North America (41 of 50 states), 4\% from Europe, 3\% from Asia, 2\% from South America, and 1\% from Australia. Most respondents (86\%) completed an orthopaedic surgery residency, followed by plastic surgery (10\%) and general surgery (3\%) residencies. Additionally, 96\% completed a specialized hand surgery fellowship. Other demographic variables are summarized in -Table 1. Additionally, a significant portion of respondents (90\%) utilized the Lichtman classification stage and the type of ulnar variance in deciding treatment strategy for Kienböck disease.

The distribution of treatment options ranged from a trial of nonoperative management (i.e., splinting or case immobilization) to operative reconstructive and salvage procedures, summarized in - Table $\mathbf{2}$. When presented with a patient with Stage I Kienböck disease, 218 surgeons (74\%) would initially trial splinting or cast immobilization for an average of 
Table 1 Demographics of respondents

\begin{tabular}{|c|c|c|}
\hline Residency training & $\mathrm{n}=299$ & \\
\hline General surgery & 10 & $3 \%$ \\
\hline Orthopaedic surgery & 258 & $86 \%$ \\
\hline Plastic surgery & 31 & $10 \%$ \\
\hline Hand fellowship trained? & 297 & \\
\hline Yes & 286 & $96 \%$ \\
\hline No & 11 & $4 \%$ \\
\hline Region of practice & 273 & \\
\hline North America & 248 & $91 \%$ \\
\hline Europe & 11 & $4 \%$ \\
\hline South America & 4 & $1.5 \%$ \\
\hline Asia & 8 & $3 \%$ \\
\hline Australia & 2 & $0.7 \%$ \\
\hline U.S. practice & 241 & $88 \%$ \\
\hline New England & 68 & $28 \%$ \\
\hline Northwest & 12 & $5 \%$ \\
\hline Southwest & 28 & $12 \%$ \\
\hline Midwest & 39 & $16 \%$ \\
\hline Central/Mountain & 27 & $11 \%$ \\
\hline South & 67 & $28 \%$ \\
\hline Years in practice & 287 & \\
\hline $1-5$ & 6 & $2 \%$ \\
\hline $6-10$ & 34 & $12 \%$ \\
\hline $11-20$ & 117 & $41 \%$ \\
\hline $21-30$ & 93 & $32 \%$ \\
\hline $31-40$ & 30 & $10 \%$ \\
\hline$>41$ & 7 & $2 \%$ \\
\hline Arthroscopies/year & 303 & \\
\hline 0 & 43 & $14 \%$ \\
\hline$<5$ & 32 & $10 \%$ \\
\hline $5-20$ & 139 & $46 \%$ \\
\hline$>20$ & 89 & $30 \%$ \\
\hline
\end{tabular}

7 weeks. The remaining 77 surgeons (26\%) elected for operative treatment, of whom 39 (51\%) preferred a radial shortening osteotomy with a median shortening of $2 \mathrm{~mm}, 13$ (17\%) a vascularized bone graft, and 13 (17\%) a core decompression. Other procedures were chosen by $5 \%$ or fewer of surgeons.

Sixty percent of respondents indicated that they would alter their treatment strategy if the patient's diagnosis was Stage II Kienböck disease. Thirty-seven percent would still perform a splinting trial; however, the majority of respondents instead opted for operative treatment and most favored a radial shortening osteotomy.

When presented with a patient with Stage IIIa Kienböck disease with $3 \mathrm{~mm}$ of negative ulnar variance, the most common treatment chosen (69\%) was a radial shortening osteotomy with a median shortening of $3 \mathrm{~mm}$. Only 15 surgeons (5\%) chose to trial splinting and the remaining responses did not show a preferential treatment, with vascularized bone grafting (10\%), intercarpal arthrodesis (4\%), and PRC (4\%) being the alternative treatments.

The responses for Stage IIIa Kienböck disease with $2 \mathrm{~mm}$ of positive ulnar variance were more heterogeneous and failed to demonstrate a preference for a single modality. The most common procedures were capitate shortening osteotomy (28\%), vascularized bone graft (18\%), and radial wedge osteotomy (12\%).

The majority of surgeons selected a salvage procedure for Stage IIIb Kienböck disease. This included PRC (42\%), intercarpal arthrodesis (21\%), and total wrist fusion (11\%). The respondents who opted for a nonsalvage intervention would perform a radial shortening osteotomy (12\%), a vascularized bone grafting (6\%), or a trial of splinting (4\%).

If Stage IV Kienböck disease was diagnosed, as opposed to Stage IIIb disease, 56\% would not change their treatment of these patients. Seventy-one percent would perform a PRC, $16 \%$ a total wrist fusion, with $8 \%$ choosing an intercarpal arthrodesis or a radial shortening osteotomy.

\section{Discussion}

The purpose of this study was to establish the trends of practice by hand surgeons, when encountering a case of Kienböck disease. Despite more than a dozen described interventions for Kienböck disease, there was general agreement of treatment. Based on our results, the most common treatment approaches preferred at each stage of Kienböck disease are summarized in - Table 3.

Results of a European survey of orthopaedic surgeons in the United Kingdom, Germany and France on treatment options for Kienböck disease were published in $2012 .^{32}$ For Stage I Kienböck disease, radial shortening osteotomy was the overwhelmingly preferred initial therapy in the UK (68\%), France (49\%), and Germany (69\%). On the other hand, our study demonstrated that most surgeons (74\%) would initially try nonoperative management. For Stage IIIb Kienböck disease, both the UK (56\%) and France (53\%) preferred a radial shortening osteotomy, while German respondents preferred STT arthrodesis (41\%) or wrist denervation (33\%). - Fig. 1 illustrates the overall trends of Kienböck disease management at different stages.

An interesting finding in our study that highlights the rarity and lack of familiarity of this disease was the fact that $6 \%$ of surgeons would still shorten the radius even in the setting of ulnar positive variance. ${ }^{33}$ Furthermore, a frequent comment among respondents was that they had never seen or heard of a case of Kienböck disease with positive ulnar variance and requested to ascertain the degree of ulnar variance. Even though ulnar variance is clearly a determining factor for basing treatment decisions, this has not been included in the Lichtman classification for Kienböck disease. ${ }^{6}$

Bain et al have described a system of classifying Kienböck disease using arthroscopy; it proposes to describe the extent of disease more accurately than can be accomplished using 
Table 2 Summary of results by stage, number of respondents (percentage of total per stage)

\begin{tabular}{|c|c|c|c|c|c|c|}
\hline & 1 & $\|^{n}$ & IIla (-) & IIla (+) & IIIlb & $\mathrm{IV}^{\wedge}$ \\
\hline Trial of splinting & $218(74 \%)$ & $84(37 \%)$ & $15(5.1 \%)$ & $10(3.5 \%)$ & $10(3.5 \%)$ & $6(2.3 \%)$ \\
\hline 4 weeks & 45 & & 3 & 2 & 0 & \\
\hline 6 weeks & 92 & & 4 & 4 & 6 & \\
\hline 8 weeks & 39 & & 3 & 2 & 2 & \\
\hline 12 weeks & 33 & & 3 & 2 & 1 & \\
\hline 16 weeks & 2 & & 0 & & 0 & \\
\hline$>16$ weeks & 2 & & 0 & 0 & 0 & \\
\hline Core decompression & $13(4.4 \%)$ & $12(5.2 \%)$ & $7(2.4 \%)$ & $20(7.1 \%)$ & $3(1 \%)$ & $0(0 \%)$ \\
\hline Radius & 10 & & 7 & 17 & 2 & \\
\hline Both radius and ulna & 2 & & 0 & 3 & 1 & \\
\hline Vascularized bone graft & $13(4.4 \%)$ & $19(8.4 \%)$ & $28(9.6 \%)$ & $51(18 \%)$ & $16(5.7 \%)$ & $4(1.6 \%)$ \\
\hline Pedicled transplant from the distal radius & 11 & & 22 & 44 & 13 & \\
\hline Direct implantation of metacarpal artery & 1 & & 5 & 6 & 2 & \\
\hline Free vascularized graft & 1 & & 1 & 1 & 1 & \\
\hline External fixation & $1(0.3 \%)$ & $1(0.4 \%)$ & $3(1 \%)$ & $4(1.4 \%)$ & $0(0 \%)$ & $0(0 \%)$ \\
\hline 6 weeks & 0 & & 1 & 1 & 0 & \\
\hline 8 weeks & 0 & & 2 & 1 & 0 & \\
\hline Pinning & $3(0.3 \%)$ & $1(0.4 \%)$ & $0(0 \%)$ & $6(2.1 \%)$ & $4(1.4 \%)$ & $0(0 \%)$ \\
\hline Radial shortening osteotomy & $39(13 \%)$ & $69(30 \%)$ & $201(69 \%)$ & $17(6 \%)$ & $34(12.1 \%)$ & $9(3.5 \%)$ \\
\hline $0 \mathrm{~mm}$ (width of saw) & 4 & & 3 & 4 & 6 & \\
\hline $1 \mathrm{~mm}$ & 3 & & 3 & 0 & 4 & \\
\hline $2 \mathrm{~mm}$ & 21 & & 55 & 7 & 15 & \\
\hline $3 \mathrm{~mm}$ & 7 & & 129 & 5 & 6 & \\
\hline $4 \mathrm{~mm}$ & 0 & & 11 & 1 & 0 & \\
\hline Radial wedge osteotomy & $4(1.3 \%)$ & $4(1.7 \%)$ & $4(1.4 \%)$ & $32(11 \%)$ & $1(0.3 \%)$ & $2(0.8 \%)$ \\
\hline Decrease radial inclination angle & 4 & & 2 & 27 & 1 & \\
\hline Increase radial inclination angle & 0 & & 1 & 5 & 0 & \\
\hline Capitate shortening osteotomy & $3(1 \%)$ & $1(0.4 \%)$ & $5(1.7 \%)$ & $79(28 \%)$ & $3(1.1 \%)$ & $1(0.4 \%)$ \\
\hline Intercarpal arthrodesis & $0(0 \%)$ & $3(1.3 \%)$ & $12(4.1 \%)$ & $26(9.3 \%)$ & $59(21 \%)$ & $10(3.9 \%)$ \\
\hline Capitohamate & 0 & & 0 & 1 & 1 & \\
\hline Lunetotriquetral & 0 & & 0 & 2 & 1 & \\
\hline Scaphocapitate & 0 & & 6 & 17 & 43 & \\
\hline STT & 0 & & 5 & 6 & 11 & \\
\hline Lunate excision & $0(0 \%)$ & $0(0 \%)$ & $0(0 \%)$ & $0(0 \%)$ & $2(0.7 \%)$ & $1(0.4 \%)$ \\
\hline Without replacement & 0 & & 0 & 0 & 2 & \\
\hline Proximal row carpectomy & $0(0 \%)$ & $0(0 \%)$ & $10(3.4 \%)$ & $28(10 \%)$ & $119(42 \%)$ & $181(71 \%)$ \\
\hline Total wrist fusion & $1(0.3 \%)$ & $0(0 \%)$ & $5(1.7 \%)$ & $6(2.1 \%)$ & $30(10.7 \%)$ & $42(16 \%)$ \\
\hline Surgical, unspecified & & $33(15 \%)$ & & & & \\
\hline Total number per stage & 295 & 227 & 290 & 279 & 281 & 256 \\
\hline
\end{tabular}

$\wedge$ = Stages II and IV were presented via additional questions posed after stages I and IIIb questions were asked, respectively. Respondents were asked via free-text to describe how their surgical plan would change; therefore, subcategory responses are unavailable for these two stages.

only plain radiographs. ${ }^{34,35}$ Respondents in our study cited this system multiple times. The status of the lunate articular cartilage determined by arthroscopic evaluation may be an important consideration for surgical treatment.
Similar to other studies of this nature, there are several limitations of our research. There is a possible selection bias, as only ASSH members were surveyed. However, we feel this is still a representative population, as these cases will likely be 
Table 3 Most common treatments based on survey results

\begin{tabular}{|l|l|l|}
\hline Stage & Classification criteria & Treatment \\
\hline I & $\begin{array}{l}\text { Normal except for the possibility of either a } \\
\text { linear or a compression fracture }\end{array}$ & $\begin{array}{l}\text { Trial of splinting or cast immobilization. Radial } \\
\text { shortening osteotomy for persistent } \\
\text { symptoms. }\end{array}$ \\
\hline II & Definite density changes apparent in the lunate & $\begin{array}{l}\text { Same as stage I, with radial shortening osteot- } \\
\text { omy more aggressively pursued }\end{array}$ \\
\hline IIIa (-) & $\begin{array}{l}\text { Collapse of entire lunate without fixed scaphoid } \\
\text { rotation, negative ulnar variance }\end{array}$ & $\begin{array}{l}\text { Radial shortening osteotomy } \\
\text { rotation, positive ulnar variance }\end{array}$ \\
\hline IIla (+) & $\begin{array}{l}\text { Collapse of entire lunate without fixed scaphoid } \\
\text { rotation }\end{array}$ & $\begin{array}{l}\text { Attempt vascularized bone grafting of lunate or } \\
\text { capitate shortening osteotomy. Otherwise, } \\
\text { PRC. }\end{array}$ \\
\hline IIIb & $\begin{array}{l}\text { Stage III with generalized degenerative changes } \\
\text { in the carpus }\end{array}$ & $\begin{array}{l}\text { Salvage procedures (PRC, intercarpal } \\
\text { arthrodesis) }\end{array}$ \\
\hline IV & PRC if possible, total wrist fusion otherwise \\
\hline
\end{tabular}

seen or referred to a hand specialist. Additionally, our study included 33 international surgeons belonging to the society. Similarly, we did not discriminate between lengths of practice, which can result in individuals failing to respond if they have not had sufficient exposure to this rare disease. Even with all these limitations, we obtained a large number of respondents $(n=375)$ with diverse demographics including age and length of practice, and we believe that the data obtained offer insight into the individual treatment preference for managing this rare disease. An additional limitation of this study, which may have added to the heterogeneity of responses, is that there were no radiographic images provided with each case. We believed this would simplify the objectiveness of our study by removing radiographic interpretation from the question, but certain treatment options can only be selected given the presence or absence of specific carpal pathology. For example, PRC can be a successful salvage option, but the capitate head must be mostly free of degenerative changes, while in cases of mild arthritic changes, partial resection of the capitate or interposition arthroplasty of dorsal wrist capsule can be performed as adjuvants. ${ }^{36,37}$

In conclusion, the majority of surgeons use the Lichtman staging system for guiding the treatment of Kienböck's disease, while also basing their treatment approach on ulnar variance. Most surgeons perform a radial shortening osteotomy for Stage I disease after failed conservative treatment, and this is the favorite treatment for Stage II and Stage IIIa with ulnar negative variance. Stage IIla with positive ulnar variance was treated heterogeneously, with capitate shortening osteotomy being most common, followed by vascularized bone grafting, although there was no clear consensus. Salvage procedures predominated in Stage IIIb and IV and included PRC, intercarpal arthrodesis, and total wrist fusion. This study shows the challenges faced by hand surgeons

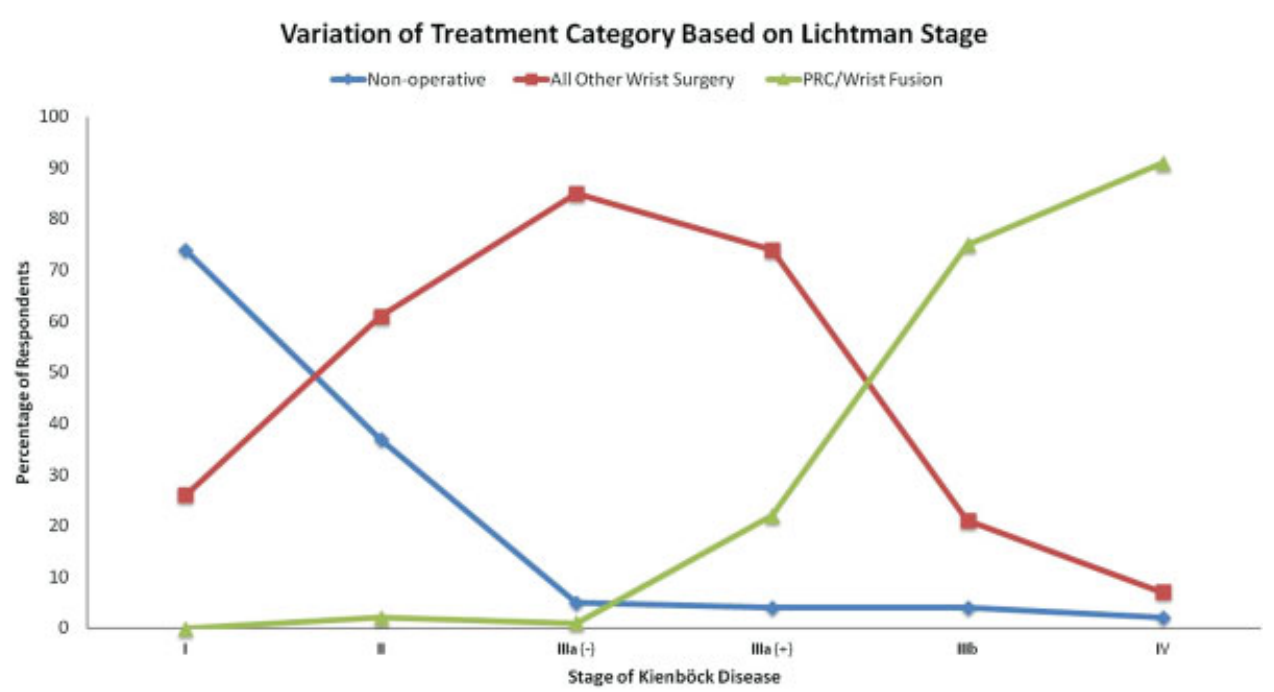

Fig. 1 Variation of treatment category based on Lichtman stage. Overall percentages of preferred approaches as grouped into nonoperative, nonsalvage (all other wrist surgery), and salvage (PRC/intercarpal arthrodesis/wrist fusion) demonstrate the trend toward of incremental increase in aggressiveness as the stage of Kienböck disease at presentation progresses. 
treating Kienböck disease and highlights the need for highlevel research to be performed on this rare disease.

\section{Note}

This study was funded by a grant from the Orthopaedic Scientific Research Foundation.

\section{Conflict of Interest}

None

\section{Acknowledgment}

The authors are indebted to the 375 respondents who took the time to complete the survey and provide insight into their handling of this complex surgical problem.

\section{References}

1 Kienböck R. Über traumatische Malazie des Mondbeins und ihre folgezustände: Entartungsformen und Kompressionsfrakturen. Fortschr Geb Röntgenstr 1910;16:77-103

2 Peltier LF. The classic. Concerning traumatic malacia of the lunate and its consequences: degeneration and compression fractures. Privatdozent Dr. Robert Kienböck. Clin Orthop Relat Res 1980; (149):4-8

3 Mennen U, Sithebe H. The incidence of asymptomatic Kienböck's disease. J Hand Surg Eur Vol 2009;34(3):348-350

4 Hultén O. Uber anatomische Variationen der Handgelenkknochen. Acta Radiol 1928;9:155-168

5 Stahl F. On lunatomalacia. A clinical and roentgenological study, specially on its pathogenesis and the late results of inmobilization treatment. Acta Chir Scand 1947;Suppl 126:1-133

6 Lichtman DM, Mack GR, MacDonald RI, Gunther SF, Wilson JN. Kienböck's disease: the role of silicone replacement arthroplasty. J Bone Joint Surg Am 1977;59(7):899-908

7 Desser TS, McCarthy S, Trumble T. Scaphoid fractures and Kienbock's disease of the lunate: MR imaging with histopathologic correlation. Magn Reson Imaging 1990;8(4):357-361

8 Imaeda T, Nakamura R, Miura T, Makino N. Magnetic resonance imaging in Kienböck's disease. J Hand Surg [Br] 1992;17(1):12-19

9 Lichtman DM, Lesley NE, Simmons SP. The classification and treatment of Kienbock's disease: the state of the art and a look at the future. J Hand Surg Eur Vol 2010;35(7):549-554

10 Ogawa T, Nishiura Y, Hara Y, Okamoto Y, Ochiai N. Correlation of histopathology with magnetic resonance imaging in Kienböck disease. J Hand Surg Am 2012;37(1):83-89

11 Goeminne S, Degreef I, De Smet L. Reliability and reproducibility of Kienbock's disease staging. J Hand Surg Eur Vol 2010;35(7):555-557

12 Goldfarb CA, Hsu J, Gelberman RH, Boyer MI. The Lichtman classification for Kienböck's disease: an assessment of reliability. J Hand Surg Am 2003;28(1):74-80

13 Jafarnia K, Collins ED, Kohl HW III, Bennett JB, Ilahi OA. Reliability of the Lichtman classification of Kienböck's disease. J Hand Surg Am 2000;25(3):529-534

14 Hashizume $\mathrm{H}$, Asahara $\mathrm{H}$, Nishida $\mathrm{K}$, Inoue $\mathrm{H}$, Konishiike $\mathrm{T}$. Histopathology of Kienböck's disease. Correlation with magnetic resonance and other imaging techniques. J Hand Surg [Br] 1996; 21(1):89-93

15 Schmitt R, Heinze A, Fellner F, Obletter N, Strühn R, Bautz W. Imaging and staging of avascular osteonecroses at the wrist and hand. Eur J Radiol 1997;25(2):92-103
16 Beredjiklian PK. Kienböck's disease. J Hand Surg Am 2009;34(1): 167-175

17 Innes L, Strauch RJ. Systematic review of the treatment of Kienböck's disease in its early and late stages. J Hand Surg Am 2010; 35(5):713-717, 717.e1-717.e4

18 Begley BW, Engber WD. Proximal row carpectomy in advanced Kienböck's disease. J Hand Surg Am 1994;19(6):1016-1018

19 Bertini S, Capanna R, Vitale C. Use of the Swanson prosthesis in Kienböck's disease. Ital J Orthop Traumatol 1982;8(1): 33-41

20 Chen W, Wang J, Pan J, Zhang Q Shao X, Zhang Y. Primary results of Kienböck's disease treated using balloon kyphoplasty system. Arch Orthop Trauma Surg 2012;132(5):677-683

21 El-Mowafi H, El-Hadidi M, El-Karef E. Proximal row carpectomy: a motion-preserving procedure in the treatment of advanced Kienbock's disease. Acta Orthop Belg 2006;72(5):530-534

22 Hermans S, Degreef I, De Smet L. Vascularised bone graft for Kienböck disease: preliminary results. Scand J Plast Reconstr Surg Hand Surg 2007;41(2):77-81

23 Hohendorff B, Mühldorfer-Fodor M, Kalb K, van Schoonhoven J, Prommersberger KJ. STT arthrodesis versus proximal row carpectomy for Lichtman stage IIIB Kienböck's disease: first results of an ongoing observational study. Arch Orthop Trauma Surg 2012; 132(9):1327-1334

24 Inoue G. Capitate-hamate fusion for Kienböck's disease. Good results in 8 cases followed for 3 years. Acta Orthop Scand 1992; 63(5):560-562

25 Kakinoki R, Matsumoto T, Suzuki T, Funakoshi N, Okamoto T, Nakamura T. Lunate plasty for Kienböck's disease: use of a pedicled vascularised radial bone graft combined with shortening of the capitate and radius. Hand Surg 2001;6(2):145-156

26 Kawoosa AA, Dhar SA, Mir MR, Butt MF. Distraction osteogenesis for ulnar lengthening in Kienbock's disease. Int Orthop 2007; 31(3):339-344

27 Lu L, Gong X, Liu Z, Zhang Z. Capitate transposition to replace necrotic lunate bone with a pedicle for Kienbock's disease: review of 30 cases. Chin Med J (Engl) 2003;116(10):1519-1522

28 Meena D, Saini N, Kundanani V, Chaudhary L, Meena D. Distraction histiogenesis for treatment of Kienbock's disease: A 2- to 8-year follow-up. Indian J Orthop 2009;43(2):189-193

29 Mehrpour SR, Kamrani RS, Aghamirsalim MR, Sorbi R, Kaya A Treatment of Kienböck disease by lunate core decompression. J Hand Surg Am 2011;36(10):1675-1677

30 Nakamura R, Watanabe K, Tsunoda K, Miura T. Radial osteotomy for Kienböck's disease evaluated by magnetic resonance imaging. 24 cases followed for 1-3 years. Acta Orthop Scand 1993;64(2): 207-211

31 Sundberg SB, Linscheid RL. Kienböck's disease. Results of treatment with ulnar lengthening. Clin Orthop Relat Res 1984;(187): 43-51

32 Stahl S, Santos Stahl A, Rahmanian-Schwarz A, et al. An international opinion research survey of the etiology, diagnosis, therapy and outcome of Kienböck's disease (KD). Chir Main 2012;31(3): 128-137

33 Blanco RH, Blanco FR. Osteotomy of the radius without shortening for Kienböck disease: a 10-year follow-up. J Hand Surg Am 2012; 37(11):2221-2225

34 Bain GI, Begg M. Arthroscopic assessment and classification of Kienbock's disease. Tech Hand Up Extrem Surg 2006;10(1):8-13

35 Bain GI, Munt J, Turner PC. New advances in wrist arthroscopy. Arthroscopy 2008;24(3):355-367

36 Ilyas AM. Proximal row carpectomy with a dorsal capsule interposition flap. Tech Hand Up Extrem Surg 2010;14(3):136-140

37 Salomon GD, Eaton RG. Proximal row carpectomy with partial capitate resection. J Hand Surg Am 1996;21(1):2-8 